\title{
Fabrication and characterisation of polymer based solar cells
}

\author{
L.H. Slooff* ${ }^{1}$, S. Böhme, ${ }^{1}$ W. Eerenstein, ${ }^{1}$ S.C. Veenstra, ${ }^{1}$ W. Verhees, ${ }^{1}$ J.M. Kroon, ${ }^{1}$ T. Söderström ${ }^{2}$ \\ ${ }^{1}$ ECN - Solar Energy, P.O. Box 1, 1755 ZG Petten, the Netherlands \\ ${ }^{2}$ University of Neuchâtel, Institute of Microtechnology, Rue A.-L. Breguet 2,CH-2000 Neuchâtel, \\ Switzerland
}

\begin{abstract}
Tandem solar cells, in which two individual cells are stacked on top of each other, offer the potential to increase the efficiency significantly compared to a single cell on the same area. To reach maximum efficiency, each cell in the stack must have a distinctive spectral response and the current in each cell must be similar. This requires smart selection of materials, proper cell design and appropriate layer thickness. Tandem polymer solar cells can be made by processing two individual cells from solvent based liquids, separated by a recombination layer. Potential candidates for the recombination layer are 1) a combination of a $\mathrm{ZnO}$ layer and a pH-neutral PEDOT:PSS layer, 2) a TiOx layer combined with a normal PEDOT:PSS layer. We will discuss the properties of the suggested recombination layers. To determine the performance of tandem cells, accurate spectral response measurements are crucial. Spectral response measurements of a polymer tandem cell show that the response of each subcell can be measured only when a bias light with sufficient intensity and suitable spectrum is applied. We will discuss the special requirements for the spectral response set-up that are needed in order to successfully discriminate between the responses of each subcell.
\end{abstract}

Keywords: Spectral response measurements, tandem solar cells, polymer solar cells, recombination layer

\section{INTRODUCTION}

Organic and polymer based solar cells have been studied intensively [1,2], as their production costs are expected to be significantly lower than that for conventional silicon based solar cells. However, two main hurdles that have to be overcome are the relatively low efficiency and stability of polymer based solar cells. The efficiency of a polymer solar cell consisting of a blend of a light absorbing electron donating polymer and [C60]PCBM electron acceptor well above $2 \%$ was first reported in 2001 [3], and the highest reported values to date are above 5\% [4].

Polymer based tandem cells are only recently coming into play with the publication of a $6.5 \%$ polymer tandem cell by Kim et al.[5] According to theoretical calculations by Dennler et al.[6], the efficiency of such a tandem cell could increase to over $9 \%$ by optimization of the layer thicknesses of the two sub cells and by increasing the performance of the limiting sub cell, e.g. by adding alkanethiols as in ref. [5,6]. This calculation was done for existing materials and is thus a realistic target. On the other hand, if one could adjust the energy levels of the polymers and fullerenes at random, a polymer based tandem cell with optimized materials combination is expected to achieve 15\%.[7] To achieve these efficiencies, it is important that all layers in the tandem solar cell work optimal. The contacts of the tandem cell can be made from the same materials as in a single junction device, but an additional layer is needed to connect the top and bottom cell, the so-called recombination layer. The fabrication of polymer based tandem cells is done preferably via an all-solution processing route. In this approach, the solution for deposition of the top cell might affect the already deposited bottom cell. For this reason it is important to shield the bottom cell from the solution that is used for the top cell. Ideally, this shielding layer also acts as the recombination layer between the two cells. In this paper we will discuss the requirements for the recombination layer and we will address several possible solutions.

Another important aspect of a tandem cell concerns the proper characterization of the devices. For single junction devices, characterization is rather straightforward, although great care has to be taken in determining the correct spectral mismatch factor (MM) of a device [2,8] and the exact active cell area [2]. Tandem cells on the other hand are much more difficult to characterize. Again, a correct MM factor has to be determined, but the spectral response (SR) measurements that are needed to calculate the MM factor require a more sophisticated approach. We will discuss in detail the requirements for correct SR measurements of a tandem cell and will show initial results on an inorganic tandem cell using an adapted SR setup. 


\section{EXPERIMENTAL}

A polymer based tandem device was made from a mechanical stack (ms) of two single junction polymer: fullerene cells [9] (see Fig. 1). The bottom cell consists of a blend of poly(9,9-didecanefluorene-alt-(bisthienylene)benzothiadiazole) (PF10TBT, for structure see ref [10]) and [C60]PCBM and the top cell is an MDMOPPV:[C60]PCBM blend. The electrical contact on the MDMO-PPV:PCBM layer consisted of $\operatorname{LiF}(1 \mathrm{~nm}) / \mathrm{Al}(2.5$ $\mathrm{nm}) / \mathrm{Au}(12.5 \mathrm{~nm})$ and was semitransparent. The complete device structure is given in Fig. 6. An indium tin oxide (ITO) coated glass substrate was first thoroughly cleaned and subsequently a PEDOT:PSS Baytron P AI4083 from HC Starck) layer was spincoated on top. Then the active layer of the top cell was applied by spincoating from a 0.5 wt. \% PF10TBT:PCBM (1:4) solution in CB stirred overnight at $70{ }^{\circ} \mathrm{C}$ and from a 0.75 wt \% MDMOPPV:PCBM (1:4) solution in CB stirred overnight at $75^{\circ} \mathrm{C}$. The $\mathrm{LiF} / \mathrm{Al}$ and $\mathrm{LiF} / \mathrm{Al} / \mathrm{Au}$ contact were thermally evaporated.

Single cells of PF10TBT and MDMO-PPV have also been fabricated with a $\mathrm{pH}$ neutral layer of PEDOT:PSS (Orgacon, batch 5541073, pH=7, 1.2 wt \%, Agfa Gevaert NV (a kind gift of the Technical University of Eindhoven). The spincoating conditions were the same as for devices made with standard PEDOT. Integrated tandem cells have been made by subsequently depositing standard PEDOT:PSS, PF10TBT:PCBM, ZnO, pH neutral PEDOT and PF10TBT:PCBM, or by applying MDMO-PPV:PCBM and PF10TBT:PCBM as the active layers. Thicknesses of the active layers were approximately $150 \mathrm{~nm}$ and $100 \mathrm{~nm}$ for the top and bottom layers respectively. All layers have been deposited by spincoating as described above. LiF/Al contacts were thermally evaporated on top.

Current-voltage (I/V) measurements were done in a setup containing a Keithley 2400 SourceMeter wired to a sample holder in a nitrogen-filled glove box. The sample was illuminated by a halogen lamp. An automated rotating filter wheel was used to record the current densities at various wavelengths for external quantum efficiency (EQE) measurement. A silicon reference cell with known spectral response was used for calibration purposes. This enabled the measurement program on the computer to calculate an estimation of the short-circuit current of the organic solar cell under 1000 $\mathrm{W} / \mathrm{m}^{2}$, AM1.5 illumination, by taking into account the overlap between the EQE spectrum and the AM1.5 spectrum.

\section{IV MEASUREMENTS OF POLYMER SINGLE JUNCTION AND TANDEM CELLS}

\subsection{Influence of recombination layer}

The mechanically stacked tandem cell is a first step toward the fabrication of polymer tandem cells. As it requires a semi transparent electrode a significant proportion (approximately 20\% [12]) of the light is absorbed by this electrode. To overcome this, a monolithic tandem cell can be made with a more transparent recombination layer.

Here we studied the effect of a $\mathrm{ZnO}$ and pH-neutral PEDOT:PSS recombination layer, which can be deposited completely by solution processing [11]. The influence of $\mathrm{pH}$-neutral PEDOT on the Voc has also been studied for single cells with PF10TBT:PCBM and for single cells with MDMO-PPV:PCBM. This is shown in Fig.2. For PF10TBT:PCBM devices, $\mathrm{pH}$-neutral PEDOT has a large influence on the Voc, which drops from $1 \mathrm{~V}$ for standard PEDOT:PSS to 0.70 V for $\mathrm{pH}$-neutral PEDOT:PSS as shown in Fig. 2a. For MDMO-PPV:PCBM devices the effect is less pronounced, with a drop from 0.84 to $0.70 \mathrm{~V}$, shown in Fig. 2b. This effect on Voc is related to the electronic levels of pH-neutral PEDOT.

$\mathrm{J} / \mathrm{V}$ curves of tandems cells consisting of PFTBT as the active layers and tandems consisting of MDMO-PPV:PCBM and PF10TBT:PCBM as the active layers are shown in Fig. 3. The measured Voc of the tandem cells is $1.68 \mathrm{~V}$ for the tandem consisting of the two PF10TBT:PCBM layers and 1.54 V for the tandem consisting of a MDMO-PPV layer and 


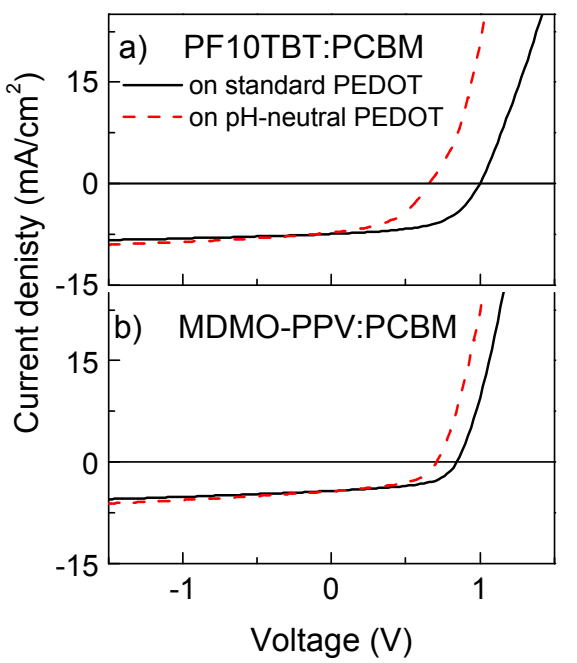

Fig. 2. I/V curves of a) PF10TBT:PCBM cells on standard and on $\mathrm{pH}$ neutral PEDOT, resulting in a $\mathrm{V}_{\mathrm{oc}}$ of $1 \mathrm{~V}$ and $0.7 \mathrm{~V}$ respectively and of b) MDMO-PPV:PCBM cells on standard and on $\mathrm{pH}$ neutral PEDOT, resulting in a $\mathrm{V}_{\mathrm{oc}}$ of $0.84 \mathrm{~V}$ and $0.7 \mathrm{~V}$ respectively.

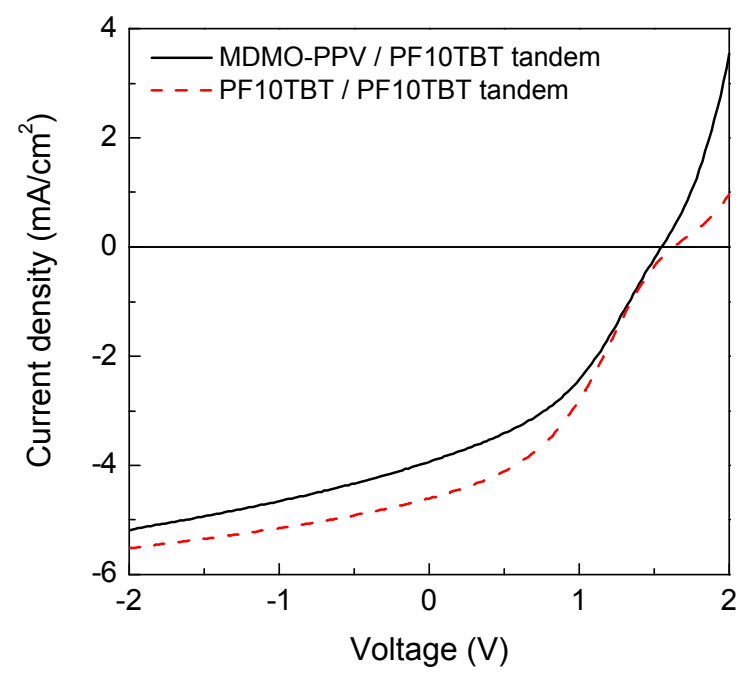

Fig. 3. I/V curves of an MDMO-PPV/PF10TBT tandem cell and a PF10TBT/PF10TBT tandem cell

a PF10TBT:PCBM layer. These $\mathrm{V}_{\text {oc }}$ values are the sum of the $\mathrm{V}_{\text {oc }}$ values of the individual subcells, i.e. $1.0 \mathrm{~V}+0.70 \mathrm{~V}$ for the PF10TBT layers on standard and on $\mathrm{pH}$ neutral PEDOT:PSS respectively and $0.84 \mathrm{~V}+0.70 \mathrm{~V}$ for the MDMOPPV layer on standard PEDOT and PF10TBT on $\mathrm{pH}$ neutral PEDOT. The measured current density for the tandem consisting of two PF10TBT layers is $4.6 \mathrm{~mA} / \mathrm{cm}^{2}$ measured under a halogen lamp (MPP $\left.=2.8 \mathrm{~mW} / \mathrm{cm}^{2}\right)$, resulting in an estimated AM1.5 current density of $3.7 \mathrm{~mA} / \mathrm{cm}^{2}$ (estimate based on the known mismatch for a single junction PF10TBT cell). For the thickness combination of $100 \mathrm{~nm} / 150 \mathrm{~nm}$ for the front and back cell this value corresponds to a calculated value of $3.8 \mathrm{~mA} / \mathrm{cm}^{2}$ [12]. If the voltage drop of $0.3 \mathrm{~V}$ resulting from the application of $\mathrm{pH}$-neutral PEDOT could be prevented, a significant increase in the MPP could be achieved from 2.8 to $4 \mathrm{~mW} / \mathrm{cm}^{2}$.

The voltage drop does not occur when normal PEDOT is employed. In that case, $\mathrm{ZnO}$ is not suitable as it dissolves when the acidid solutions are spincoated on top. A promising candidate to replace $\mathrm{ZnO}$ is TiOx [5]. TiOx can be processed from nanoparticle dispersions or from titanium isopropoxide precursor solutions. In the latter case, the precursor reacts with water from the air. To prevent rapid hydrolysis (which leads to non uniform layers), stabilizers such as ethanolamine and 2-methoxyethanol are added [5]. Attempts to reproduce this method have so far been unsuccessful. Single junctions with TiOx between the PF10TBT and the counter electrode showed a strongly reduced current. The reduced current indicates that the TiOx acts as a blocking layer. This could be due to a partial hydrolysis of the titanium isopropoxide precursor or a too thick layer. This is subject to further investigation.

\section{SPECTRAL RESPONSE MEASUREMENTS}

\subsection{Background information}

From the $\mathrm{I} / \mathrm{V}$ measurements above, the short circuit current $\left(\mathrm{I}_{\mathrm{sc}}\right)$, open circuit voltage $\left(\mathrm{V}_{\mathrm{oc}}\right)$ and the fill factor $(\mathrm{FF})$ can be obtained, with which the solar cell efficiency can be determined:

$$
\eta=\frac{\mathrm{I}_{\mathrm{sc}} \times \mathrm{V}_{\mathrm{oc}} \times \mathrm{FF}}{\text { incident power }}
$$

However, an accurate efficiency can only be determined if the I/V measurement was done correctly. The current of a solar cell is directly depending on the irradiation spectrum. As a result, different solar simulators with different lamps will give different currents in an I/V measurement. In order to be able to compare the results, a standard solar spectrum 
has been defined, the Air Mass 1.5 Global spectrum (AM1.5G [13]). When measuring the current of the cell using a lamp with a different spectrum, the data have to be adapted for AM1.5G illumination. The correct procedure is described in ref. [2] and [8] but will be described here shortly. First the spectral response of a calibrated reference cell $\left(\mathrm{S}_{\mathrm{R}}(\lambda)\right)$ and the test cell $\left(\mathrm{S}_{\mathrm{T}}(\lambda)\right)$ must be measured as well as the lamp spectrum of the solar simulator $\left(\mathrm{E}_{\mathrm{S}}(\lambda)\right)$. These measurements, together with the tabulated AM1.5G spectrum $\left(\mathrm{E}_{\mathrm{R}}(\lambda)\right)$ are then used to calculated the spectral mismatch factor MM:

$$
\begin{aligned}
M M & =\frac{\int E_{R}(\lambda) S_{R}(\lambda) \partial \lambda}{\int E_{S}(\lambda) S_{R}(\lambda) \partial \lambda} \times \frac{\int E_{S}(\lambda) S_{T}(\lambda) \partial \lambda}{\int E_{R}(\lambda) S_{T}(\lambda) \partial \lambda} \\
= & \frac{I_{s c} \text { of the refcel under AM1.5G }}{I_{s c} \text { of the refcel under simulator }} \times \frac{I_{s c} \text { of the testcel under simulator }}{I_{s c} \text { of the testcel under AM1.5G }}
\end{aligned}
$$

In which:

$$
\mathrm{S}(\lambda)=\frac{\text { photocurrent generated by the solar cell }\left(\mathrm{A} / \mathrm{m}^{2}\right)}{\text { incident light power }\left(\mathrm{W} / \mathrm{m}^{2}\right)}
$$

The spectral response can be dependent on illumination intensity. For this reason a correct measurement of the spectral response of the reference cell and the test cell must be done under continuous illumination to maintain one sun working conditions.

Once $\mathrm{M}$ has been determined, the solar simulator is adjusted up to the point where:

$$
\mathrm{I}_{\mathrm{sc} \mathrm{ref}}^{\text {simulator }}=\frac{1}{\mathrm{M}} \mathrm{I}_{\mathrm{sc} \text { ref }}^{\mathrm{AM} 1.5 \mathrm{G}}
$$

Now the solar simulator can be used to do an accurate I/V measurement and the efficiency can be calculated using Eq. 1. Note, that in the case of tandem solar cells, it is crucial that the spectrum is matched to AM1.5G, as the repartition of currents between the top and bottom cells will have a strong influence on the FF of the tandem cell.

\subsection{Measurement setup for spectral response measurements}

The procedure described above clearly indicates the importance of an accurate spectral response measurement. For single junction solar cells a typical spectral response measurement uses a white light source in combination with a chopper and a filter wheel or monochromator to create monochromatic illumination of the solar cell. Bias light ensures the one sun working conditions. The response of the cell to the chopped monochromatic light is then measured using a lock-in amplifier.If a tandem solar cell is measured in a setup as described for single junction solar cells, the result will not indicate the spectral response of the tandem in which the cells are connected in series.[14] The reason for this is found in the way the current is generated in a tandem solar cell. If the two cells in the tandem are connected in series, Kirchoff's law states that the current from the tandem cell is determined by the lowest current of the two sub cells. If we now look at the situation in the spectral response setup for a tandem cell with complementary absorption spectra, as shown in Fig. $1 \mathrm{a}$, it can be seen that at low wavelengths only the top cell is absorbing and will generate current. As a result, due to Kirchoff's law, the tandem will generate zero current. The same holds at high wavelengths, where only the bottom cell is absorbing. As a result, the spectral response measurement of the tandem cell will only show a response in the region where both cells generate current, i.e. in the region where the absorption spectra overlap (see Fig. 4a). In order to overcome this problem, one of the two cells must be selectively illuminated, with intensity high enough to prevent current limitation by this cell (also called bias illumination). Then the spectral response of the other cell can be measured (see Fig. 4b). Similarly the spectral response of the first cell can be measured by selectively illuminating the second cell. In our setup the selective illumination was applied by either halogen lamps in combination with a color filter, or by (a ring with) LED's of the desired wavelength. 


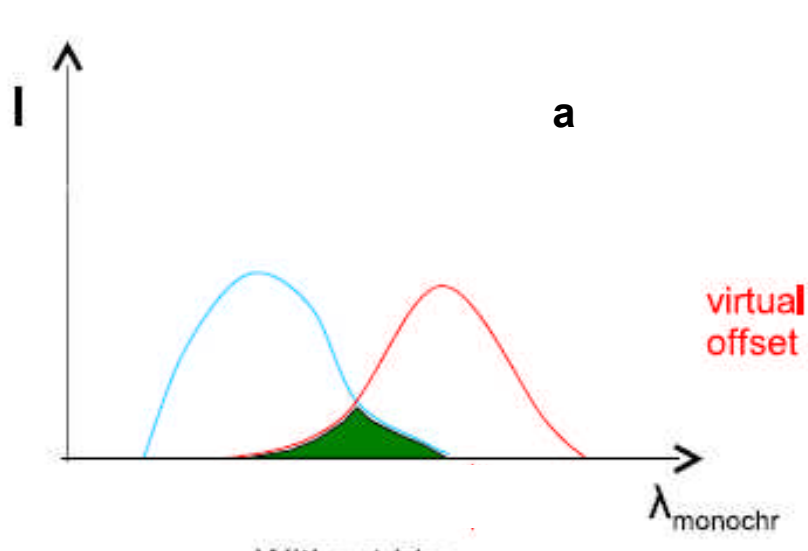

Without bias

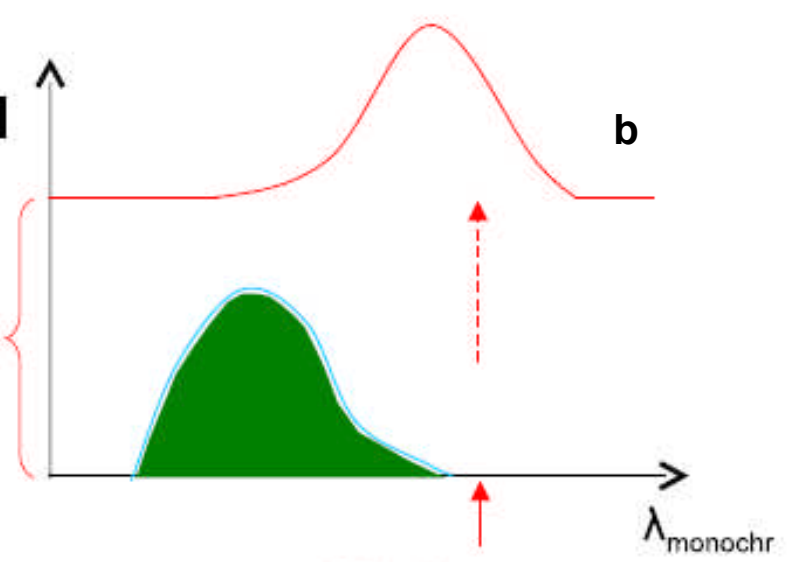

With bias

Fig 4: (a) absorption spectra of the top cell (blue line) and bottom cell (red line) of a tandem cell. The filled area represents the result of a spectral response measurement on such a tandem solar cell without bias illumination. (b) The result of a spectral response measurement on a tandem cell when the bottom cell is biased by bias illumination in its absorption region. The filled area shows the spectral response of the top cell.

However, the selective bias illumination also introduces an error itself if measured at $\mathrm{I}_{\mathrm{sc}}$. By selectively illuminating e.g the top cell, this cell operates at $\mathrm{V}_{\text {oc,top }}$, but the whole tandem operates at $\mathrm{V}=0 \mathrm{~V}$. As a result, the bottom cell will operate at $-\mathrm{V}_{\text {oc,top }}$. For cells with a low FF, this will result in a measured $\mathrm{I}_{\mathrm{sc}}$ that is higher than the actual $\mathrm{I}_{\mathrm{sc}}$. Measuring a tandem at $\mathrm{V}=0$ under selective illumination will thus overestimate the $\mathrm{I}_{\mathrm{sc}}$ of the measured sub cell. For this reason a bias voltage has to be applied. The proper bias voltage equals the $V_{o c}$ of the cell that is not measured, which can be determined from single junction cells. Else, the ASTM approximation $\mathrm{V}_{\text {bias }}=0.5 \times \mathrm{V}_{\text {oc,tandem }}[15]$ can be used.

From the above it is clear that for measuring the spectral response of tandem cells, the measurement setup has to be extended with selective bias illumination and a voltage supply to apply the bias voltage to ensure short circuit conditions.

\subsection{Spectral response measurement tests on inorganic tandem cells}

To test our spectral response setup for tandem cells, we used a micromorph tandem cell that was made at the University of Neuchatel $[16,17]$. The device structure is presented in Fig. 5 . It consists of a plastic foil as a substrate, covered with an thin silver and $\mathrm{ZnO}$ layer layer. The bottom cell is a n-i-p junction of microcrystalline silicon $(\mu \mathrm{c}-\mathrm{Si}: \mathrm{H})$ and the top cell a n-i-p junction of amorphous silicon (a-Si:H). A boron doped $\mathrm{ZnO}$ is used as the transparent counter electrode [18]. The SR measurements on this tandem as performed by the University of Neuchatel are shown in Fig. 6. Clearly the spectra of the two sub cells are nicely complementary. The a-Si:H absorb from $400 \mathrm{~nm}$ to $800 \mathrm{~nm}$ and the $\mu \mathrm{c}-\mathrm{Si}: \mathrm{H}$ from $400 \mathrm{~nm}$ to $1100 \mathrm{~nm}$ making it possible to use selective illumination for measuring this tandem cell.

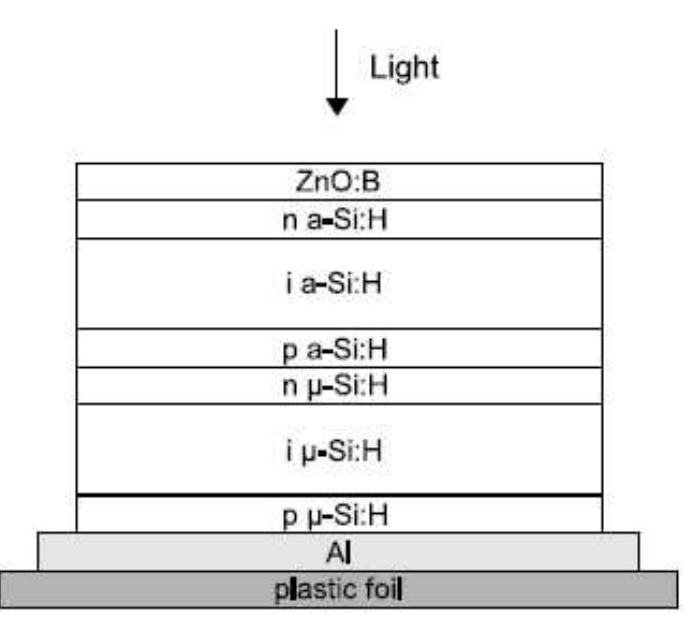

Fig. 5. Layer stack of a micromorph tandem cell (stack of amorpohous and microcrystalline cells) that was processed at the University of Neuchatel, with an a-Si:H top cell and a $\mu-\mathrm{Si}: \mathrm{H}$ bottom cell. A plastic foil serves as substrate and silver/ZnO as back contact. 
First we tried to measure the bottom, i.e. $\mu \mathrm{c}-\mathrm{Si}: \mathrm{H}$ cell, by applying selective illumination of the top using a combination of a halogen lamp with a broad bandpass filter and a lens to focus the light into a spot that was large enough to cover the complete cell. In this measurement we varied the illumination intensity to see when the top cell is not current limiting and a correct SR curve of the bottom cell could be measured. The result is shown in Fig. 7. The bar at the bottom axis of the figure indicates the bandpass region of the filter. From this Fig. it can be seen that without the selective illumination, the SR of the tandem is only that part where both cells are absorbing. Note that there is also a small response in the range $700-800 \mathrm{~nm}$ where the top cell is not absorbing. This is an artifact of the measurement, and we are working on improvements in the setup to remove it, but it does not influence the conclusions for the SR measurement. When selective illumination is applied at low intensity $(\mathrm{U}=4 \mathrm{~V}$, which is

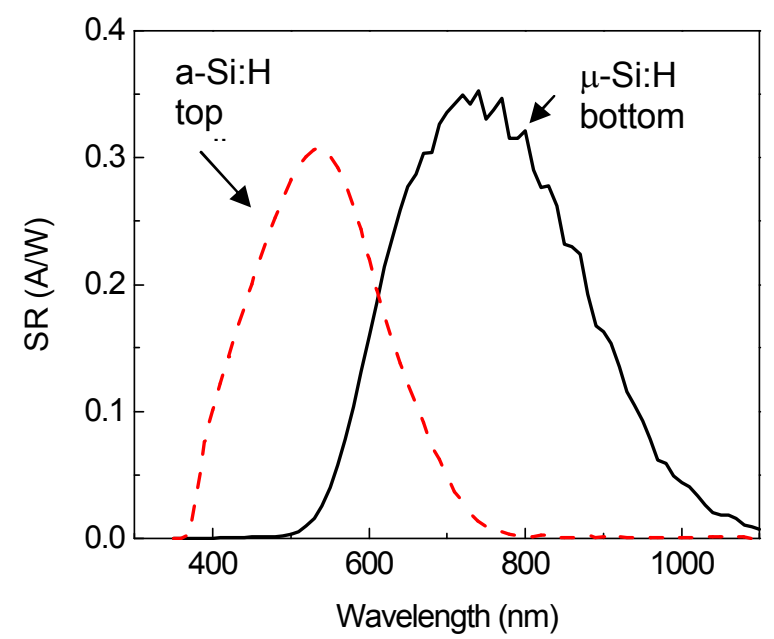

Fig. 6. SR of the a-Si:H top cell and the $\mu$-Si:H bottom cell as measured by the University of Neuchatel the voltage applied at the halogen lamp), the top cell is still clearly current limiting, as the SR measurement hardly changes when compared to the situation without selective illumination. When the intensity is increased, $U=6 \mathrm{~V}$, the $\mathrm{SR}$ begins to resemble the SR that was measured at Neuchatel, but at $790 \mathrm{~nm}$ and $880 \mathrm{~nm}$ there is still a pronounced deviation. Increasing the illumination intensity further, $U=7 \mathrm{~V}$ and $\mathrm{U}=12 \mathrm{~V}$, improves the $\mathrm{SR}$ further. The discrepancies at $790 \mathrm{~nm}$ and $880 \mathrm{~nm}$ reduce and at $\mathrm{U}=12 \mathrm{~V}$ they disappear completely. This shows that between $\mathrm{U}=7$ and $\mathrm{U}=12 \mathrm{~V}$ the illumination intensity becomes high enough to change from a current limiting top cell to a current limiting top cell, which is the situation one needs for a correct SR measurement of the bottom cell. Apparently one needs a higher illumination intensity to achieve this preferred situation at certain specific wavelengths. The reason for this can be found in the spectral distribution of the white light source. This lamp has a specific high intensity emission line at $880 \mathrm{~nm}$. At this wavelength mainly the bottom cell is absorbing. So at a lower wavelength we can have the situation that the bottom cell is already current limiting, but at $880 \mathrm{~nm}$ the bottom cell shows an increased current due to the emission line of the lamp, thereby making the top cell current limiting, resulting in a lower SR value than expected.

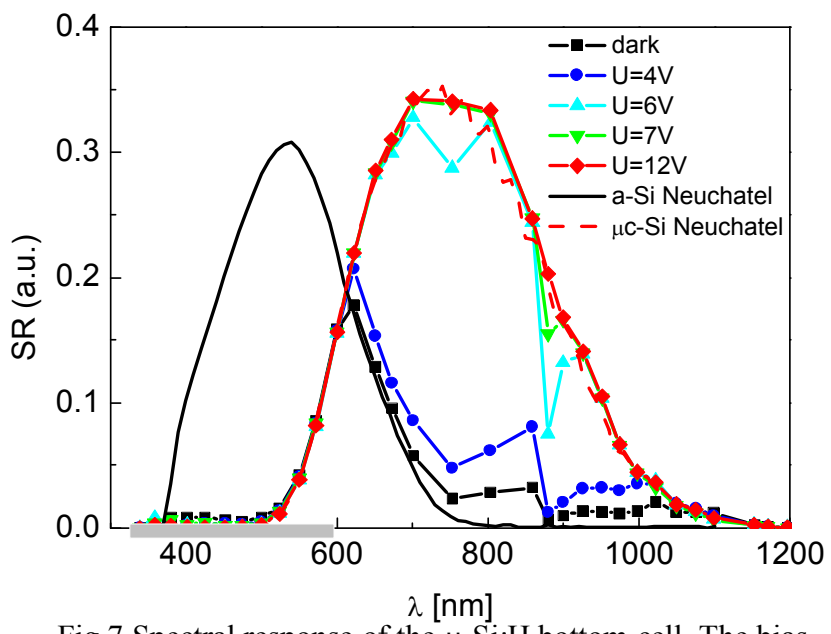

Fig.7 Spectral response of the $\mu$-Si:H bottom cell. The bias light was applied to the a-Si:H top cell via a halogen lamp and a broad band filter which transmits all light below $600 \mathrm{~nm}$ and has its main intensity at $500 \mathrm{~nm}$

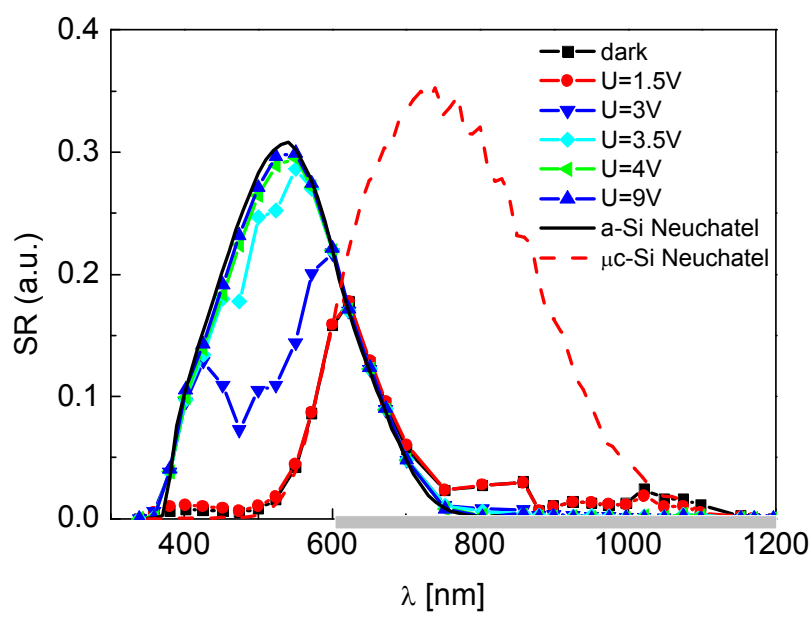

Fig. 8. Spectral response of the a-Si:H top cell. The bias light was applied to the $\mu \mathrm{c}-\mathrm{Si}: \mathrm{H}$ top cell via a halogen lamp and a broad band filter which absorbs all light below $610 \mathrm{~nm}$ and has its main intensity at $700 \mathrm{~nm}$. 


\section{Measuring the top cell}

Using the same approach, the top cell was measured by applying a broadband pass filter as indicated at the bottom of Fig. 8. Again a clear transition is observed when going from low illumination intensities $(\mathrm{U}=1,5 \mathrm{~V}$ and $3 \mathrm{~V})$ to higher illumination intensities $(\mathrm{U}=4 \mathrm{~V})$. At an illumination intensity corresponding to $\mathrm{U}=4 \mathrm{~V}$, the correct $\mathrm{SR}$ of the top cell was already observed.

\section{SPECTRAL RESPONSE MEASUREMENT ON POLYMER TANDEM CELLS}

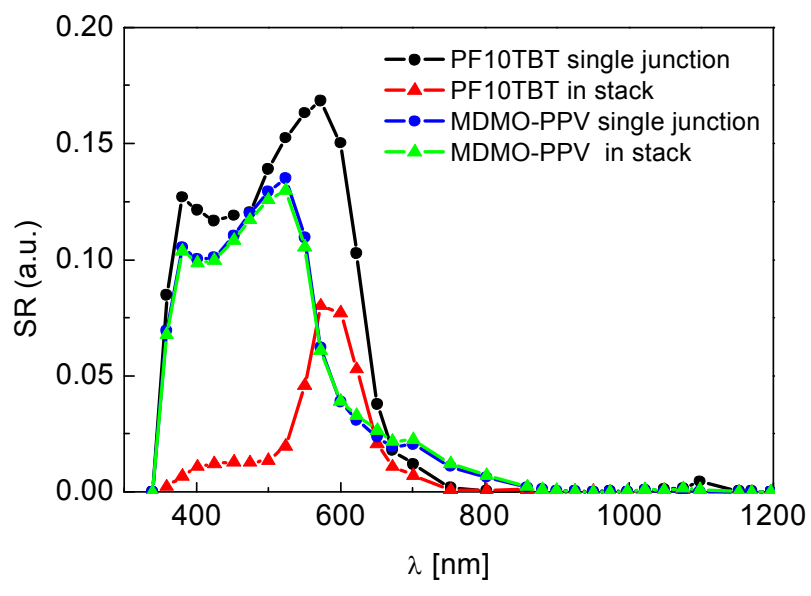

Fig. 9. Spectral response of the mechanically stacked tandem cell. No bias light was applied. The SR of the MDMO-PPV:PCBM cell in the tandem stack was equal to a separate MDMO-PPV cell. .

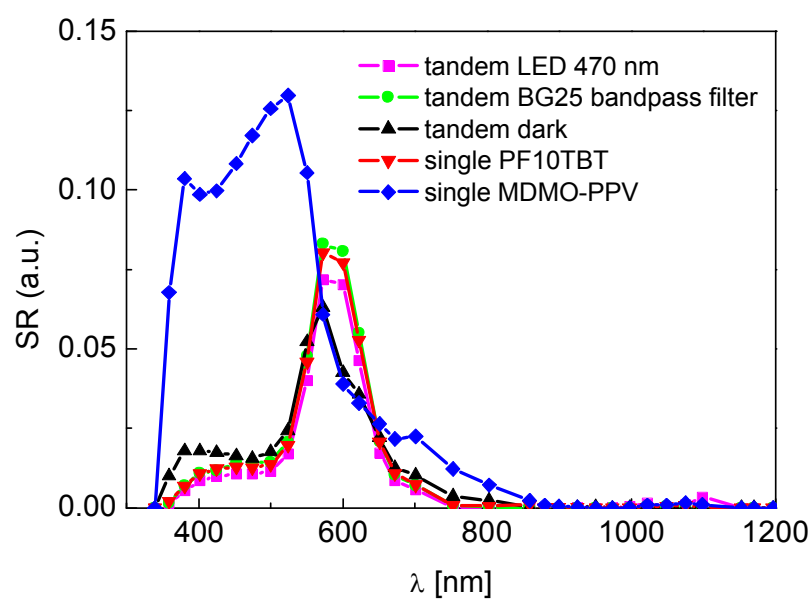

Fig. 10. Spectral response of the bottom PF10TBT:PCBM cell in the mechanically stacked tandem cell, measured by applying a bias light with LEDs at 470 $\mathrm{nm}$ to the top MDMO-PPV cells.

\subsection{Measuring the bottom cell}

First single cell measurements were performed on the single junction cells alone, as well as in the mechanical stack configuration. The results are shown in Fig. 9. As can be seen, the SR curve of the single junction MDMO-PPV:PCBM cell (contacts 5 and 6 in Fig.1) is similar for the cell alone and in the mechanical stack (contacts 3 and 6), but the PF10TBT cell strongly suffers from absorption loss in the stacked configuration. The bottom cell is expected to be easier to measure, as according to the results in Fig. 10, this cell is already the current limiting cell almost over the whole spectral range. When using weak LED bias illumination at $470 \mathrm{~nm}$, the SR of the bottom cell of the stack in the two-terminal measurement is almost identical to the output of the bottom cell in the fourterminal situation as can be seen in Fig. 10. We also did a measurement with halogen lamp illumination in combination with a bandpass filter. The result is presented in Fig. 10, showing that this type of illumination is also able to measure the correct SR of the bottom cell. So both the LED illumination, as well as the halogen lamp with filter illumination, results in a correct SR measurement.

\subsection{Measuring the top cell}

For a correct measurement of the top cell, it is necessary to apply selective illumination in the range where the bottom cell is current limiting. Fig. 9. shows that this is only a narrow region around $600 \mathrm{~nm}$. So either we should have a LED at this wavelength, or a narrow bandpass filter. Unfortunately, the filter we had did not suit the above mentioned requirement, which was confirmed by the measurements, but the available $590 \mathrm{~nm}$ LED should be at the correct wavelength. However, the MDMO-PPV cell also absorbs at this wavelength and it was not possible to generate a large enough current in the PF10TBT cell in order to make the MDMO-PPV cell current limiting. 


\section{CONCLUSIONS}

Polymer solar cells consisting of PF10TBT:PCBM and MDMO-PPV:PCBM show a reduced Voc of $0.7 \mathrm{~V}$ when processed in devices with $\mathrm{pH}$ neutral PEDOT. This has been related to the energy levels of the neutral PEDOT. All solution processed tandem cells have been fabricated with a recombination layer consisting of $\mathrm{ZnO}$ and $\mathrm{pH}$ neutral PEDOT. Recombination layers of TiOx prove to be more difficult to synthesize.

It has been shown that selective illumination for tandem cells is capable of inducing current limitation in only one sub cell. This in turn leads to a tandem SR being equal to the SR of that sub cell as measured in a single junction device. A prerequisite is good spectral matching of the selective illumination with the spectral window, in which the sub cell not being measured has a higher photocurrent.

Broadband filters with a strong halogen lamp are a good choice for the selective illumination source in cases where a broad spectral window for illumination is available, i.e. in the tested micromorph Si tandem cell. LEDs are a better choice for sub cell combinations that offer only a narrow spectral window, i.e. in the case of the tested MDMO-PPV / PF10TBT polymer tandem.

\section{ACKNOWLEDGEMENTS}

This work has been supported by the Senter/Novem in the EOS project Zomer (EOSLT03026).

\section{REFERENCES}

[1] MRS Bulletin 30, 1-60 (2005)

[2] V. Shrotriya et al, "Accurate measurement and characterisation of organic solar cells", Adv. Funct. Mat. 16, 20162023 (2006)

[3] S.E. Shaheen et al, "2.5\% efficient plastic solar cell”, Appl. Phys. Lett 78, 841-843 (2001)

[4] M.A. Green, K. Emery, Y. Hishikawa and W. Warta, "Solar Cell Efficiency Tables (Version 31)", Prog. Photovolt: Res. Appl. 16, 61-67 (2008)

[5] J. Y. Kim, K. Lee, N. E. Coates, D. Moses, T.-Q. Nguyen, M. Dante and A. J. Heeger, "Efficient tandem polymer solar cells fabricated by all-solution processing," Science 317, 222-225 (2007)

[6] G. Dennler, K. Forberich, T. Ameri, C. Waldauf, P. Denk, and C. J. Brabec, "Design of efficient organic tandem cells: on the interplay between molecular absorption end layer sequence," J. Appl. Phys. 102, 1231096 (2007)

[7] G. Dennler, M. C. Scharber, T. Ameri, P. Denk, K. Forberich, C. Waldauf, and C. J. Brabec, "Design Rules for Donors in Bulk-Heterojunction Tandem Solar Cells?Towards 15 \% Energy-Conversion Efficiency,"Adv. Mat. 20, 579$583(2008)$

[8] J. M. Kroon, M. M. Wienk, W. J. H. verhees, and J. C. Hummelen, "Accurate efficiency determination and stability studies of conjugated polymer/fullerene solar cells", Thin Sol. Films 403-404, 223-228 (2002)

[9] V.S. Shrotriya, G. Li, Y. yao, Y. Yang, "Tandem stacking structure for polymer solar cells by using semi-transparent electrodes", Proc. of SPIE 6334, 633416 (2006)

[10] L.H. Slooff, S.C. Veenstra, J. M. Kroon, D.J.D. Moet, J. Sweelssen, M.M. Koetse, "Determining the internal quantum efficiency of highly efficient polymer solar cells through optical modeling", Appl. Phys. Lett. 90, 143506 (2007)

[11] J. Gilot, et al., "Double and triple junction polymer solar cells processed from solution", Appl. Phys. Lett. 90, 143512 (2007).

[12] W. Eerenstein, L.H. Slooff, S.C. Veenstra, J.M. Kroon, "Optical modeling as optimization tool for single and double junction polymer solar cells", Thin Sol. Films 516, 7188-7192 (2008).

[13] Datasheet for the AM1.5G spectrum was obtained from: http://rredc.nrel.gov/solar/spectra/am1.5/

[14] A. Hadipour, B. de Boer, and P. W. M. Blom, "Organic Tandem and Multi-junction Solar Cells", Adv. Funct. Mater. 18, 169-181 (2008)

[15] ASTM designation E 2236-05a: Standard Test Methods for Measurement of Electrical Performance and Spectral Response of Nonconcentrator Multijunction Photovoltaic Cells and Modules 
[16] T. Söderström, F.-J. Haug, V. Terrazzoni-Daudrix, X. Niquille, S. Perregeaux, M. Fahland, and C. Ballif, “Opencircuit voltage optimisation of amorphous silicon thin film solar cells for flexible photovoltaics " Proc. 22nd European PVSEC 1819-1822 (2007).

[17] J. Meier, U. Kroll, E. Vallat-Sauvain, J. Spitznagel, U. Graf, and A. Shah, “Amorphous solar cells, the micromorph concept and the role of VHF-GD deposition technique," Solar Energy 77, 983-993 (2004).

[18] S. Fay, U. Kroll, C. Bucher, E. Vallat-Sauvain, and A. Shah, "Low pressure chemical vapour deposition of ZnO layers for thin-film solar cells: temperature-induced morphological changes”, Solar Energy Materials and Solar Cells 86, 385-397 (2005). 